\title{
Otimização de um protocolo para micropropagação da oliveira Ascolano 315
}

\author{
Fabíola Villa1 ${ }^{1}$ Moacir Pasqual ${ }^{2}$, Gustavo de Faria Freitas ${ }^{3}$
}

\begin{abstract}
RESUMO
O objetivo foi induzir a multiplicação em explantes de oliveira. Para tanto, foram utilizados segmentos nodais de aproximadamente $2 \mathrm{~cm}$, sem folhas, oriundos de plântulas da variedade Ascolano 315 mantidas in vitro. Os segmentos foram excisados e inoculados em tubos de ensaio contendo $15 \mathrm{~mL}$ do meio de cultura Olive Medium (OM) suplementado com $2 \mathrm{~g} \mathrm{~L}^{-1}$ de carvão ativado, quatro concentrações de 6-benzilaminopurina (BAP) e quatro concentrações de água de coco verde, solidificado com 5,5 $\mathrm{g} \mathrm{L}^{-1}$ de ágar e $\mathrm{pH}$ ajustado para 5,8 antes da autoclavagem. O meio de cultura foi autoclavado a $121{ }^{\circ} \mathrm{C}$ e $1 \mathrm{~atm}$ durante 20 minutos. O delineamento experimental foi inteiramente casualizado, em esquema fatorial $4 \times 4$. Durante 70 dias, os explantes foram mantidos em sala de crescimento a $25 \pm 1^{\circ} \mathrm{C}$, intensidade luminosa de $32 \mathrm{ì} \mathrm{mol} \mathrm{m} \mathrm{m}^{-2} \mathrm{~s}^{-1} \mathrm{e}$ fotoperíodo de 16 horas. O meio de cultura OM adicionado de $1,0 \mathrm{mg} \mathrm{L}^{-1}$ de BAP e $100 \mathrm{~mL}$ $\mathrm{L}^{-1}$ de água de coco proporcionou maior comprimento e biomassa fresca da parte aérea. Maior número de raízes foi obtido com 0,5 mg L-1 de BAP associado a $25 \mathrm{~mL} \mathrm{~L}^{-1}$ de água de coco. O aumento da concentração de BAP e da dose de água de coco incrementa a biomassa dos calos formados.
\end{abstract}

Palavras-chave: Cultivo in vitro, água de coco, BAP, Olea europaea L.

\section{ABSTRACT}

\section{Optimization of a protocol for the micropropagation of olive tree cv. Ascolano 315}

Micropropagation can be a viable technique for the multiplication of olive trees. The objective of this work was to induce multiplication in explants of olive tree. Nodal segments with $2 \mathrm{~cm}$ length, without leaves, derived from in vitro plantlets of cultivar Ascolano 315 were excised and inoculated in test tubes. The tubes contained $15 \mathrm{~mL}$ of OM (Olive medium) culture medium supplemented with $2 \mathrm{~g} \mathrm{~L}^{-1}$ of activated charcoal, 4 concentrations of 6-benzilaminopurin (BAP) and 4 concentrations of coconut water and solidified with $5.5 \mathrm{~g} \mathrm{~L}^{-1}$ of agar. The $\mathrm{pH}$ was adjusted to 5.8 before medium sterilization at $121^{\circ} \mathrm{C}$ and $1 \mathrm{~atm}$ for $20 \mathrm{~min}$. The experimental design was complete randomized in a $4 \mathrm{x} 4$ factorial scheme. The explants were kept in a growth room $25 \pm 1^{\circ} \mathrm{C}$, light intensity of $32 \mathrm{ì} \mathrm{mol} \mathrm{m} \mathrm{s}^{-1}$ and photoperiod of 16 hours, for 70 days. The culture medium OM added of $1.0 \mathrm{mg} \mathrm{L}^{-1}$ of BAP and $100 \mathrm{~mL} \mathrm{~L}^{-1}$ of coconut water provided the greatest length and biomass of the aerial part. The largest number of roots was obtained with $0.5 \mathrm{mg} \mathrm{L}^{-1}$ of BAP associated with $25 \mathrm{~mL} \mathrm{~L}^{-1}$ of coconut water.

Key words: in vitro culture, coconut water, benzilaminopurin, Olea europaea.

\footnotetext{
Recebido para publicação em dezembro de 2009 e aprovado em junho de 2010

${ }^{1}$ Engenheira-Agrônoma, Doutora. FAPEMIG/EPAMIG, Bairro Vargedo, 37517-000, Maria da Fé, Minas Gerais (MG), Brasil. fvilla2003@libero.it

${ }^{2}$ Engenheiro-Agrônomo, Doutor. Departamento de Agricultura (DAG), Universidade Federal de Lavras (UFLA), Campus Universitário, 37200-000, Lavras, MG, Brasil. mpasqual@ufla.br

${ }^{3}$ Engenheiro-Agrônomo, Mestre. Doutorando Agronomia/Fitotecnia, Bolsista CAPES, DAG, UFLA, Campus Universitário, 37200-000, Lavras, MG, Brasil. freitasgf@yahoo.com.br
} 


\section{INTRODUÇÃO}

A oliveira (Olea europaea L.) pertence à família Oleaceae. É originária da região geográfica que vai desde o sul do Cáucaso até as planícies do Irã, Palestina e zona costeira da Síria e estende-se até os países às margens do Mediterrâneo (Mesquita et al., 2006).

Na Itália, a variedade Ascolano 315 (Ascolana Tenera) é uma das mais importantes, devido as suas características de vigor vegetativo, precocidade, tolerância ao frio, maturação precoce, boa aceitação como azeitona de mesa e boa resistência ao ataque de pragas e doenças. Apesar de ser uma cultura introduzida no Brasil há muitas décadas, o cultivo da oliveira não prosperou devido à falta de estudos científicos e da adaptação tecnológica, não havendo plantio em escala comercial (Mesquita et al., 2006). Dos países da América do Sul, o Brasil é um dos maiores importadores de produtos de oliveira, sendo a Argentina um dos principais fornecedores, além da Espanha e de Portugal. Nos últimos anos, a olivicultura passou a despertar interesse entre produtores rurais, principalmente no sul de Minas Gerais (Oliveira et al., 2006).

A utilização de técnicas de cultura de tecidos com o objetivo de melhorar a rentabilidade das culturas tem-se apresentado como instrumento importante que pode ser explorado pelos pesquisadores, produzindo plantas com elevada qualidade sanitária (Souza et al., 2006).

Várias técnicas de micropropagação de oliveira têm sido reportadas por diversos autores, sendo por segmentos nodais (Santos et al., 2003), cotilédones (Brhadda et al., 2003), embriogênese somática (Trabelsi et al., 2003) ou microenxertia (Revilla et al., 1996; Peyvandi et al., 2010). Entretanto, alguns autores citam a importância de inúmeros fatores, como idade do explante ou genótipo, no sucesso da micropropagação (Rugini \& Caricato, 1995; Leva et al., 2002). Esses fatores limitam a otimização de protocolos para um número restrito de cultivares comerciais, enquanto outros genótipos ainda permanecem recalcitrantes (Ali et al., 2009).

Durante o estabelecimento in vitro, a adição de fitorreguladores tem como objetivo principal suprir as possíveis deficiências dos teores endógenos hormonais nos explantes. Simultaneamente, a adição desses reguladores estimula certas respostas como alongamento ou multiplicação da parte aérea. A adição de citocinina é favorável e pode variar bastante em função da espécie e do tipo do explante (Grattapaglia \& Machado, 2004). Segundo Santos et al. (2003), a adição de zeatina em meio de cultura Olive Medium (OM) promoveu maior número de folhas que os outros meios utilizados no cultivo da oliveira Maderensis. Melhor germinação da variedade Arbequina foi observada com a adição de zeatina em meio Wood Plant Medium (WPM) (Donini et al., 2008).
Vários elementos aditivos complexos como coco (endosperma, água, leite), peptona de carne e polpa de banana (verde ou madura) são utilizados nos meios de cultura de tecidos ou de germinação de sementes in vitro (George, 1993). Aágua de coco fornece açúcares e outros metabólitos para embriões cultivados. Vários trabalhos citam sua utilização no cultivo in vitro de espécies como orquídeas (Araujo et al., 2006) e pinhão-manso (Nunes et al., 2008).

Visando à produção de mudas de oliveira via cultura de tecidos, este trabalho teve como objetivo determinar um protocolo de micropropagação, testando concentrações de benzil amino purina (BAP) e água de coco adequadas para a oliveira Ascolano 315.

\section{MATERIAL E MÉTODOS}

Este trabalho foi desenvolvido no Laboratório de Cultura de Tecidos Vegetais do Departamento de Agricultura, Universidade Federal de Lavras (UFLA), em Lavras, Minas Gerais.

Segmentos nodais de aproximadamente $2 \mathrm{~cm}$, sem folhas, foram excisados de plântulas de oliveira Ascolano 315, oriundas de cultura de embriões. Foram inoculados assepticamente em meio OM (Rugini, 1984), suplementado com $30 \mathrm{~g} \mathrm{~L}^{-1}$ de sacarose, $2 \mathrm{~g} \mathrm{~L}^{-1}$ de carvão ativado, solidificado com 5,5 $\mathrm{g} \mathrm{L}^{-1}$ de ágar e ajustado para $\mathrm{pH}$ 5,8 antes da autoclavagem. O meio de cultura foi autoclavado a 121 ${ }^{\circ} \mathrm{C}$ e 1 atm durante $20 \mathrm{~min}$.

Foram testadas as combinações de água de coco (0; 25; 50 e $\left.100 \mathrm{~mL} \mathrm{~L}^{-1}\right)$ e do regulador $\operatorname{BAP}(0 ; 0,25 ; 0,5$ e 1,0 $\mathrm{mg} \mathrm{L}^{-1}$ ), com três repetições constituídas por quatro tubos cada uma. Os explantes foram inoculados individualmente em tubos de ensaio e transferidos para sala de crescimento com temperatura de $25 \pm 1^{\circ} \mathrm{C}$, intensidade luminosa de 32 ìmol m² s-1 e 16 horas de fotoperíodo.

Após 70 dias nessas condições de cultivo, avaliaramse o número de folhas e de raízes, comprimento da parte aérea e de raízes e a biomassa da parte aérea e de calos. $\mathrm{O}$ delineamento experimental foi inteiramente casualizado, em esquema fatorial $4 \times 4$. Os resultados foram submetidos à análise de variância e os tratamentos, comparados por regressão polinomial.

\section{RESULTADOS E DISCUSÃO}

Verificou-se interação significativa para número de folhas na ausência e com a adição de $25 \mathrm{~mL} \mathrm{~L}^{-1}$ de água de coco no meio de cultura. Na ausência de água de coco constatou-se um decréscimo de forma quadrática no número de folhas em relação ao aumento na concentração de BAP (Figura 1). Com a adição de $25 \mathrm{~mL} \mathrm{~L}^{-1}$ de água de coco, o número de folhas aumentou de forma quadrática.

Não houve efeito do regulador de crescimento e da água de coco no número de brotos, observando-se so- 


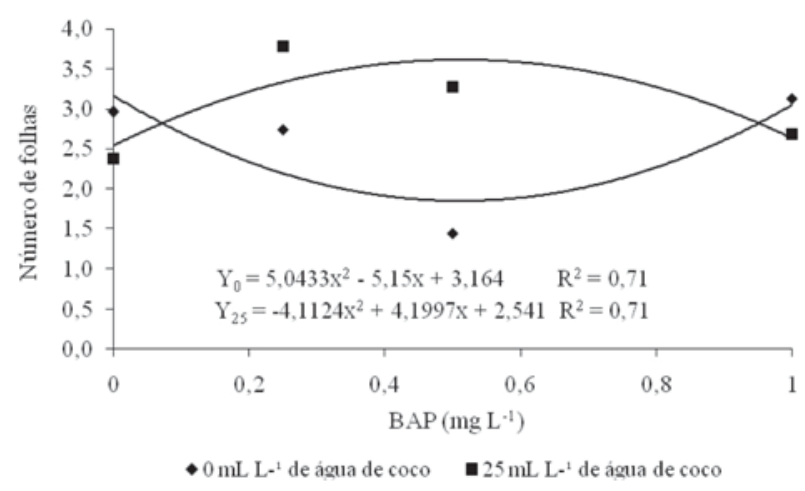

Figura 1. Número de folhas de plântulas de oliveira cultivadas in vitro em meio OM adicionado de BAP e água de coco. UFLA, Lavras, MG, 2008.

mente a alteração no crescimento em altura do único broto desenvolvido, indicando a dificuldade em se induzir brotações em oliveira (Figuras 2, 3). Esse resultado corrobora afirmações de Micheli et al. (2007) e Zacchini \& De Agazio (2004) de que a oliveira possui forte dominância apical, proliferando predominantemente por alongamento.

Observou-se crescimento quadrático no comprimento à medida que se aumentaram as concentrações de BAP adicionadas ao meio de cultura, ocorrendo maior comprimento da parte aérea com 1,0 $\mathrm{mg} \mathrm{L}^{-1}$ de BAP (Figura 2). Esses resultados discordam de Dutra et al. (2004), em que o comprimento de brotos foi maior na ausência desse regulador. Essa diferença nos resultados deve-se ao fato de que foram estudadas duas variedades distintas, em dois meios de cultura diferentes.

Estudos realizados também por Donini et al. (2008) mostraram diferenças no comprimento de brotos de três variedades de oliveira (Picual, Frantoio e Koroneiki) micropropagadas em meio de cultura OM, MS e WPM.

A adição da água de coco mostrou-se significativa para a altura dos brotos de oliveira (Figura 3). De forma linear, com o aumento nas concentrações desse aditivo verificou-se aumento no comprimento da parte aérea de Ascolano 315. Em plântulas de kiwi (Actinidia deliciosa (A. Chev.) C.F. Liang \& A.R. Ferguson) constatou-se a influência positiva da água de coco no meio MS para o comprimento das brotações in vitro (Nasib et al., 2008). O efeito estimulatório da água de coco em meio de cultivo pode ser explicado pelos altos teores de aminoácidos, compostos nitrogenados, elementos inorgânicos, vitaminas, além de hormônios vegetais, necessários ao desenvolvimento das plântulas (George, 1993).

Observou-se a influência negativa do regulador BAP no comprimento das raízes de oliveira (Figura 4). Com o aumento nas concentrações desse fitorregulador verificou-se diminuição linear no comprimento das raízes.

O número de raízes foi influenciado pela adição do regulador BAP no meio de cultura associado a 25 e $100 \mathrm{~mL} \mathrm{~L}^{-1} \mathrm{de}$

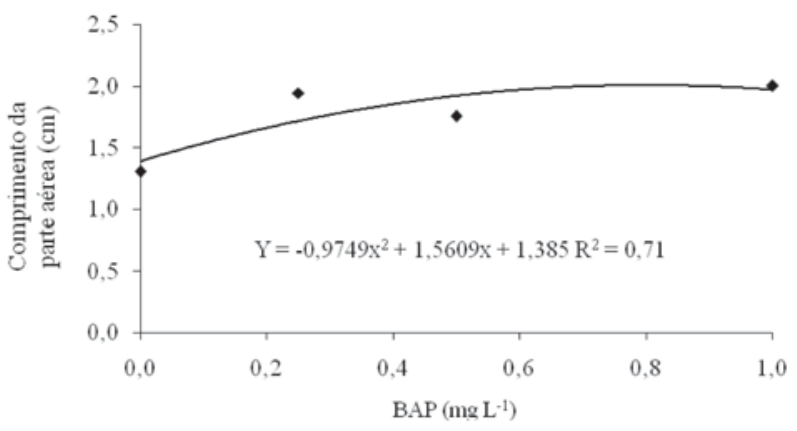

Figura 2. Comprimento da parte aérea de plântulas de oliveira cultivadas in vitro em meio OM adicionado de BAP. UFLA, Lavras, MG, 2008.

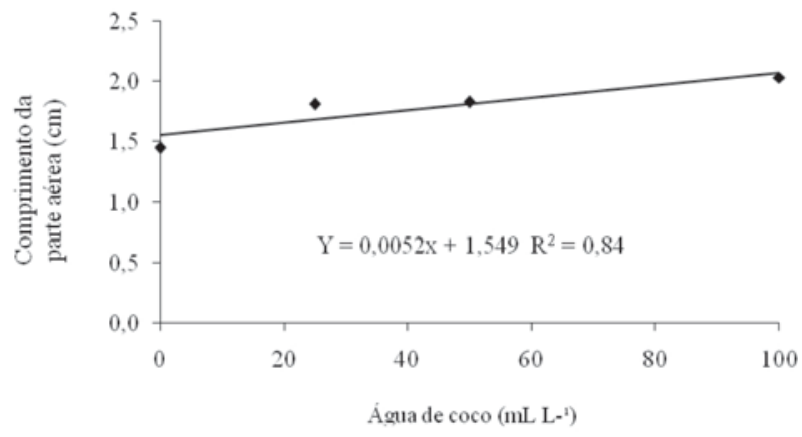

Figura 3. Comprimento da parte aérea de plântulas de oliveira cultivadas in vitro em meio OM adicionado de água de coco. UFLA, Lavras, MG, 2008.

água de coco (Figura 5). Para as duas concentrações de água de coco, as curvas comportaram-se de forma semelhante, sendo os melhores resultados observados com a adição de $0,5 \mathrm{mg} \mathrm{L}^{-1}$ de BAP associado a 25 e $100 \mathrm{~mL} \mathrm{~L}^{-1}$ de água de coco. A elevação da concentração de BAP normalmente age como fator de diminuição da elongação e emissão de raízes, em função de sua ação inibidora do sistema radicular (Grattapaglia \& Machado, 2004).

Verificou-se significância somente para BAP e água de coco separadamente em relação à biomassa fresca (Figuras 6, 7). Com o aumento nas concentrações de BAP, verificou-se aumento de forma quadrática na biomassa fresca de Ascolano 315, sendo melhores resultados observados com 1,0 $\mathrm{mg} \mathrm{L}^{-1}$ de BAP. Esses resultados discordam de Dutra et al. (2004), que constataram a ausência de BAP no meio, proporcionando maior biomassa fresca.

Essa diferença nos dados se deve, entre outros fatores, à resposta dos genótipos estudados em relação aos fatores exógenos, como, por exemplo, a utilização de diferentes meios de cultura, como MS e OM, concentrações, tipo de reguladores de crescimento e balanço hormonal (Grigoriadou et al., 2002).

A adição da água de coco no meio OM também influenciou positivamente a biomassa da parte aérea das plântulas (Figura 7). Com o aumento da dose de água de coco verificou-se aumento de forma linear na biomassa 


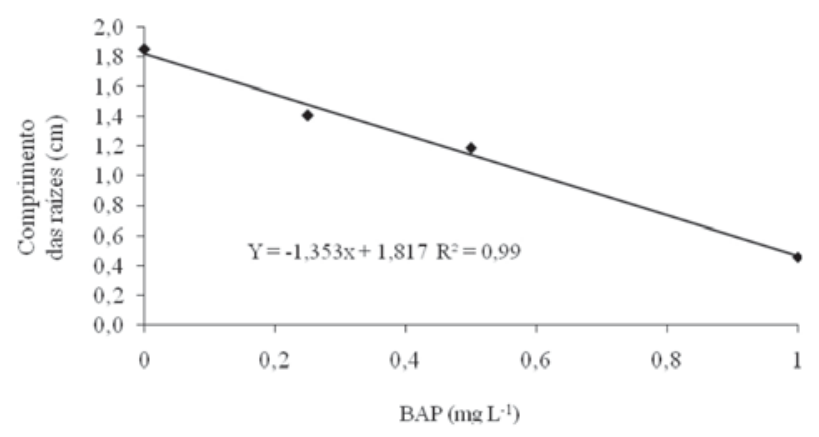

Figura 4. Comprimento das raízes de plântulas de oliveira cultivadas in vitro em meio OM adicionado de BAP. UFLA, Lavras, MG, 2008.

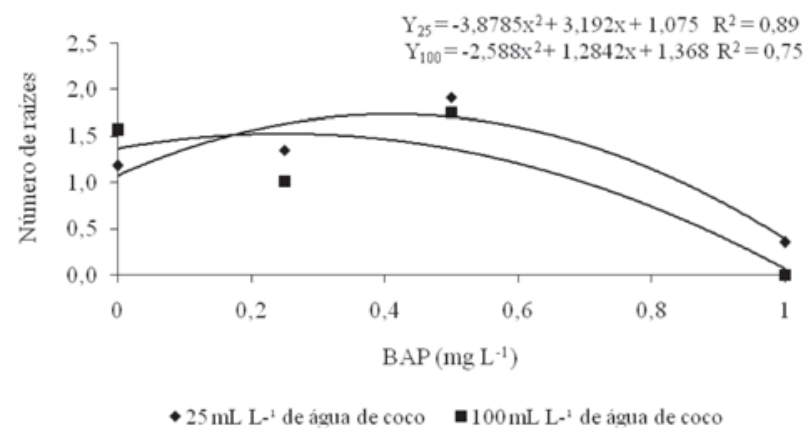

Figura 5. Número de raízes em plântulas de oliveira cultivadas in vitro em meio OM adicionado de BAP e água de coco. UFLA, Lavras, MG, 2008.

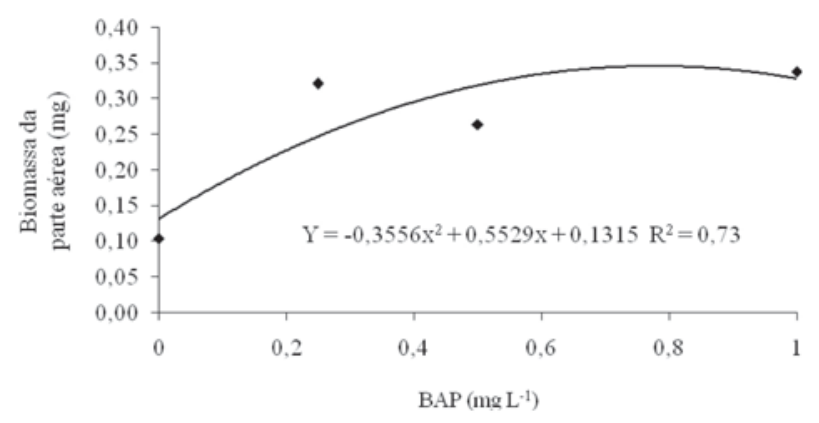

Figura 6. Biomassa da parte aérea de plântulas de oliveira cultivadas in vitro em meio OM adicionado de BAP. UFLA, Lavras, MG, 2008.

fresca. Melhores resultados foram observados com a adição de $100 \mathrm{~mL} \mathrm{~L}^{-1}$ desse elemento.

De modo geral, a capacidade tamponante dos meios nutritivos é baixa. O acréscimo de água de coco, por sua vez, aumenta essa capacidade, sendo, provavelmente, uma das causas da maior produção de massa fresca da parte aérea e maior número de folhas. Outro importante fator para explicar os resultados seria a presença de aminoácidos e citocininas na água de coco (Silva et al., 2002).

Observou-se a formação de calos na base das plântulas de oliveira, influenciada pelo BAP e pela água de coco (Figuras 8, 9). Verificou-se incremento linear da biomassa dos calos com o aumento das concentrações de BAP e da

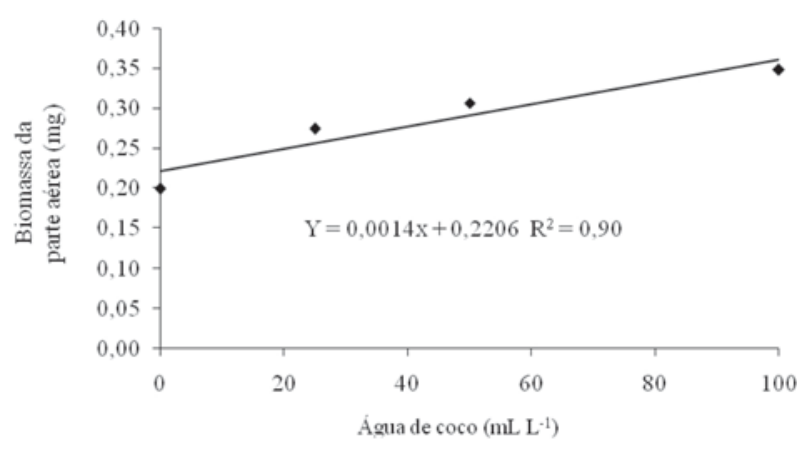

Figura 7. Biomassa da parte aérea de plântulas de oliveira cultivadas in vitro em meio OM adicionado de água de coco. UFLA, Lavras, MG, 2008.

dose de água de coco. Segundo Donini et al. (2008), um calo basal de tamanho excessivo é indesejável, por ser potencial promotor de modificações genéticas e por exaurir os nutrientes do meio de cultura em detrimento da formação de folhas e raízes.

De acordo com Ramezani \& Shekafandeh (2009), a formação de calos está muito ligada às concentrações e ao tipo de auxina no meio. Erig et al. (2004) afirmaram que a formação de calo na zona de enraizamento é indesejável, pois ele pode afetar a qualidade das raízes, principalmente no que se refere à conexão vascular com a planta.

Em trabalhos de micropropagação de oliveira, utiliza-se como regulador de crescimento a zeatina. Devido ao seu

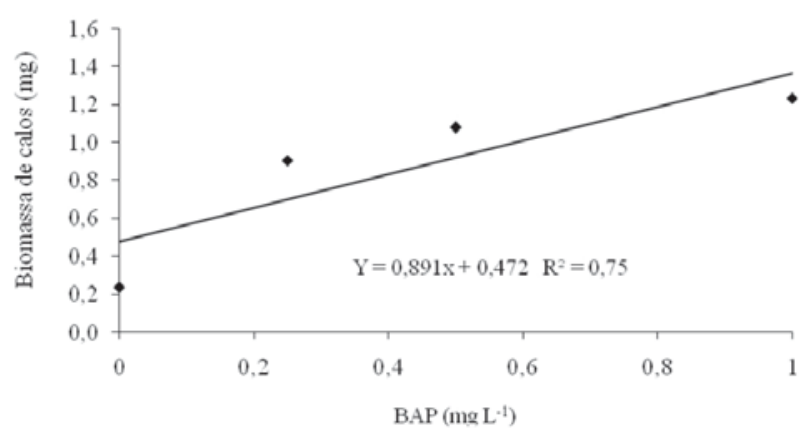

Figura 8. Biomassa de calos de plântulas de oliveira cultivadas in vitro em meio OM adicionado de BAP. UFLA, Lavras, MG, 2008.

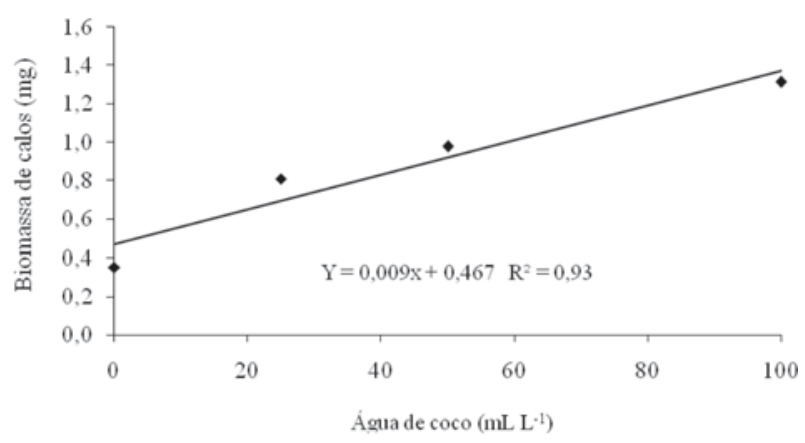

Figura 9. Biomassa de calos de plântulas de oliveira cultivadas in vitro em meio OM adicionado de água de coco. UFLA, Lavras, MG, 2008.

Rev. Ceres, Viçosa, v. 57, n.4, p. 530-534, jul/ago, 2010 
custo elevado, vários outros elementos têm sido estudados, alguns com êxito. A água de coco, por ser uma substância natural com altos níveis de zeatina, pode vir a ser um componente que substitua com êxito a zeatina sintética, como observado no presente trabalho. Alguns autores como Dutra et al. (2004) e Peixe et al. (2007) verificaram resultados positivos com a utilização de BAP e água de coco na proliferação de brotos das variedades Ascolano 315 e Galega vulgar.

Para estudos futuros, deve-se atentar ao tipo de meio de cultura empregado aos genótipos estudados e às concentrações de BAP e de água de coco adicionadas ao meio de cultura.

\section{CONCLUSÕES}

O meio de cultura OM adicionado de $1,0 \mathrm{mg} \mathrm{L}^{-1}$ de BAP e $100 \mathrm{~mL} \mathrm{~L}^{-1}$ de água de coco proporciona maior comprimento e biomassa fresca da parte aérea das plântulas de oliveira.

Maior número de raízes é obtido com $0,5 \mathrm{mg} \mathrm{L}^{-1}$ de BAP associado a $25 \mathrm{~mL} \mathrm{~L}^{-1}$ de água de coco.

O aumento da concentração de BAP e da dose de água de coco incrementa a biomassa dos calos formados.

\section{REFERÊNCIAS}

Ali A, Ahmad T, Abbasi NA \& Hafiz IA (2009) Effect of different concentrations of auxins on in vitro rooting of olive cultivar 'Moraiolo'. Pakistan Journal of Botany, 41:1223-1231.

Araujo AG, Pasqual M, Villa F \& Costa FC (2006) Água de coco e polpa de banana no cultivo in vitro de plântulas de orquídea. Revista Ceres, 53:608-613.

Brhadda N, Abousalimb A \& Walalib LDE (2003) Effets du milieu de culture et de la lumière sur l'embryogenèse somatique de l'olivier (Olea europaea L.) cv. Picholine marocaine. Fruits, 58:167-174.

Donini LP, Schuch MW, Ribeiro MF, Souza JAS \& Soares GC (2008). Estabelecimento in vitro de oliveira cv. "Arbequina" para início da micropropagação. Ciência Rural, 38:1769-1772.

Dutra LF, Oliveira AF, Fráguas CB \& Pasqual M (2004) Multiplicação in vitro de oliveira (Olea europaea L.). Ciência e Agrotecnologia, 28:220-223.

Erig AC, Schuch MW \& Chaves AC (2004) Enraizamento in vitro e aclimatização de mudas de marmeleiro Cvs. Mc e Adams, utilizadas como porta-enxerto para a pereira. Scientia Agraria, 5:61-68.

George EF (1993) Plant propagation by tissue culture. 2. ed. Exegetic, Edington. 547p.

Grattapaglia D \& Machado MA (2004) Micropropagação. In: Torres AC, Caldas LS \& Buso JA. (Eds.) Cultura de tecidos e transformações genéticas de plantas. Brasília, Embrapa-CNPH, p.183-260.

Grigoriadou K, Vasilakakis M \& Eleftheriou EP (2002) In vitro propagation of the Greek olive cultivar 'Chondrolia Chalkidikis'. Plant Cell, Tissue and Organ Culture, 71:47-54.

Leva AR, Petruccelli R \& Goretti R (2002) La micropropagazione dell'olivo: una biotecnologia per un moderno vivaismo olivicolo. Frutticoltura, 10:29-34.
Mesquita DL, Oliveira AF \& Mesquita HA (2006) Aspectos econômicos da produção e comercialização do azeite de oliva e da azeitona. Informe Agropecuário, 27:7-12.

Micheli M, Hafiz IA \& Standardi A (2007) Encapsulation of in vitro-derived explants of olive (Olea europaea L. cv. Moraiolo): II. Effects of storage on capsule and derived shoots performance. Scientia Horticulturae, 113:286-292.

Nasib A, Ali K \& Khan S (2008) An optimized and improved method for the in vitro propagation of kiwifruit (Actinidia deliciosa) using coconut water. Pakistan Journal of Botany, 40:2355-2360.

Nunes CF, Pasqual M, Santos DN, Custódio TN \& Araujo AG (2008) Diferentes suplementos no cultivo in vitro de embriões de pinhão-manso. Pesquisa Agropecuária Brasileira, 43:9-14.

Oliveira AF, Antunes LEC \& Schuch MW (2006) Caracterização morfológica de culivares de oliveira em coleção e considerações sobre o seu cultivo no Brasil. Informe Agropecuário, 27:55-62.

Peixe A, Raposo A, Lourenço R, Cardoso H \& Macedo E (2007) Coconut water and BAP successfully replaced zeatin in olive (Olea europaea L.) micropropagation. Scientia Horticulturae, 113:1-7.

Peyvandi, M, Farahzadi HN, Arbabian S, Noormohammadi Z \& Hosseini-Mazinani M (2010) Somaclonal variation among somatic-embryo derived plants of Olea europaea L. "cv. Kroneiki”. Journal of Sciences, 21:7-14.

Ramezani S \& Shekafandeh A (2009) Roles of gibberellic acid and zinc sulphate in increasing size and weight of olive fruit. African Journal of Biotechnology, 8:6791-6794.

Revilla MA, Pacheco J, Casares A \& Rodriguez R (1996) In vitro reinvigoration of mature olive trees (Olea europaea L.) through micrografting. In Vitro Cellular and Developmental BiologyPlant, 32:257-261.

Rugini E (1984) In vitro propagation of some olive (Olea europaea sativa L.) cultivars with different root-ability, and medium development using analytical data from developing shoots and embryos. Scientia Horticulturae, 24:123-134.

Rugini E \& Caricato G (1995) Somatic embryogenesis and plant recovery from mature tissue of olive cultivars (Olea europaea L.) “Canino” and "Moraiolo”. Plant Cell Reports, 14:357-260.

Santos CV, Brito G, Pinto G \& Fonseca HMAC (2003) In vitro regeneration of Olea europaea ssp. Maderensis. Scientia Horticulturae, 97:83-87.

Silva ALL, Franco ETH, Gesing JPA \& Pessoas CC (2002) Efeitos de alguns meios de cultura sobre o desenvolvimento in vitro de Cattleya tigrina A. Rich. Ex Beer - Orchidaceae. ABCTP Notícias, p.4-7.

Souza JA, Schuch MW \& Silva LC (2006) Efeito do tipo de ramo e do regime de luz fornecido à planta matriz no estabelecimento in vitro de araçazeiro cv. "Irapuã”. Ciência Rural, 36:19201922.

Trabelsi EB, Bouzid S, Bouzid M, Elloumi N, Belfeleh Z \& Benabdallah A (2003) In-vitro regeneration of olive tree by somatic embryogenesis. Journal of Plant Biology, 46:173-180.

Zacchini M \& De Agazio M (2004) Micropropagation of a local olive cultivar for germplasm preservation. Biologia Plantarum, 48:589-592. 